\title{
Participación en la construcción popular del hábitat. Una revisión del Plan Piloto para Villa 7 en Buenos Aires
}

\author{
Adriana Laura Massidda*, ${ }^{1}$ \\ Recepción: 11 de mayo de 2017 Aceptación: 25 de agosto de 2017
}

Resumen Este artículo toma un caso de estudio localizado en Buenos Aires, el Plan Piloto para la Relocalización de Villa 7 (1971-1975), como eje central para revisar los conceptos de participación y agencia en relación con la construcción popular del hábitat. En particular, el artículo propone una revisión del concepto de participación, ampliamente discutido desde los años sesenta del siglo pasado y aún en debate, a través de la idea de agencia. Se distinguen dos modalidades principales en el artículo: aquellas donde la participación es entendida como parte de un proceso más amplio de transformación social, que otorga agencia a todos los miembros de una sociedad, y aquellas en que es pensada exclusivamente como facilitadora de la resolución de un problema habitacional específico.

PALABRAS CLAVE: participación, agencia, Villa 7, Plan Piloto para la Relocalización de Villa 7, Barrio Justo Suárez, desalojo, localización.

Abstract This article takes a case study located in Buenos Aires, the Plan Piloto para la Relocalización de Villa 7, 1971-1975 (Pilot Plan for the Relocation of Shantytown \#7) as the main focus for revisiting the concepts of participation and agency in relation to grassroots housing self-construction. More specifically, the article offers a revision of the idea of participation, widely discussed since the 1960s and still under debate, through the notion of agency. The article differentiates between two approaches to participation: one where it is understood as part of a wider process of social transformation that extends agency to all members of a society; and another in which participation is exclusively understood as a tool that facilitates the resolution of specific housing problems.

KEY WORDS: participation, agency, Villa 7, Plan Piloto para la Relocalización de Villa 7, Barrio Justo Suárez, eviction, resettlement.

Centro de Estudios Urbanos y Regionales ceur/COnICET, a.massidda@conicet.gov.ar

Agradezco a René Longoni por su propuesta inicial de escribir este artículo, y a Romina Barrios, Juan Molina y Vedia, Ernesto Pastrana, Valeria Snitcofsky, Martín Carranza y Aya Alphs por los intercambios sostenidos y la orientación brindada, que fueron cruciales para comenzar a desarrollar este tema. 
E ste artículo toma un caso de estudio histórico localizado en Buenos Aires, el Plan Piloto para la Relocalización de Villa 7 (1971-1975), como eje central para revisar el concepto de participación en relación con la construcción popular del hábitat. En particular, propone una revisión del concepto de participación, ampliamente discutido desde los años sesenta y aún en debate, a través de la idea de agencia, entendida aquí como la cualidad de actuar, la capacidad de una entidad o un individuo para intervenir en una situación dada (Giddens, 1984; Latour, 2005). ${ }^{2}$ Contextualizando el Plan Piloto en su coyuntura histórica, política y social, se compara la concepción de participación que lo subyacía con aquella debatida contemporáneamente en congresos interamericanos especializados tales como los convocados por la Organización de los Estados Americanos durante las décadas de los cincuenta y sesenta. En el artículo se distinguen dos modalidades principales de participación: aquellas en las cuales la participación es entendida como parte de un proceso más amplio de transformación social, donde se busca otorgar agencia a todos los miembros de una sociedad, en particular a aquellos grupos que se han encontrado históricamente desplazados de la toma de decisiones; y aquellas en que la participación es entendida como un componente que facilita la solución focalizada de un problema habitacional específico, pero que no involucra una revisión del lugar social de los grupos a los que está dirigida ni una intención de cambio.

El Plan Piloto de Realojamiento de Villa 7 fue una iniciativa de diseño participativo para la vivienda social en la cual se integró a los habitantes en la toma de decisiones a través de todas sus etapas. En un contexto de dictadura militar y de proscripción del partido político mayoritario, el equipo interdisciplinario que coordinaba el proyecto concibió la participación popular en el diseño como una cara más de la ampliación de la participación política. Este proyecto fue propuesto y llevado a cabo por un equipo coordinado por los arquitectos Osvaldo Cedrón y Alberto Compagnucci, y proyectado en conjunto con delegadxs ${ }^{3}$ y vecinxs de la Villa 7, una urbanización informal en pequeña escala localizada en el barrio de Mataderos (El Descamisado, 1973b; Nuestra Arquitectura, 1973c; Trama, 1982; Cedrón, 2000; Comisión Municipal de la Vivienda, 1970) (figuras 1-3). El Plan Piloto ha perdurado en la memoria colectiva en Buenos Aires como una experiencia clave en lo que se refiere a la participación popular en intervenciones estatales en relación con la informalidad urbana. Atendiendo al contexto, es posible proponer que el modo en que el Plan impactó e influyó en sus contemporánexs (no solo arquitectxs

2 Desarrollaremos la conceptualización de agencia más adelante en este texto, partiendo de la discusión propuesta por Anthony Giddens y complejizándola en relación con el caso de estudio. Para la presente discusión, cabe recordar que en lo etimológico el término "agencia" se encuentra estrechamente vinculado a la idea de "hacer" o de "actuar", con origen en el latín agere (OED Online, 2016).

3 Se adopta la forma - xs para denotar el plural en género neutro, es decir, delegadxs, que sintetiza "delegadas" y "delegados". 
FIGURA 1. Barrio Justo Suárez, esquina Bragado y avenida Lisandro de la Torre (esta última de nombre Tellier en la época en que el barrio fue construido)

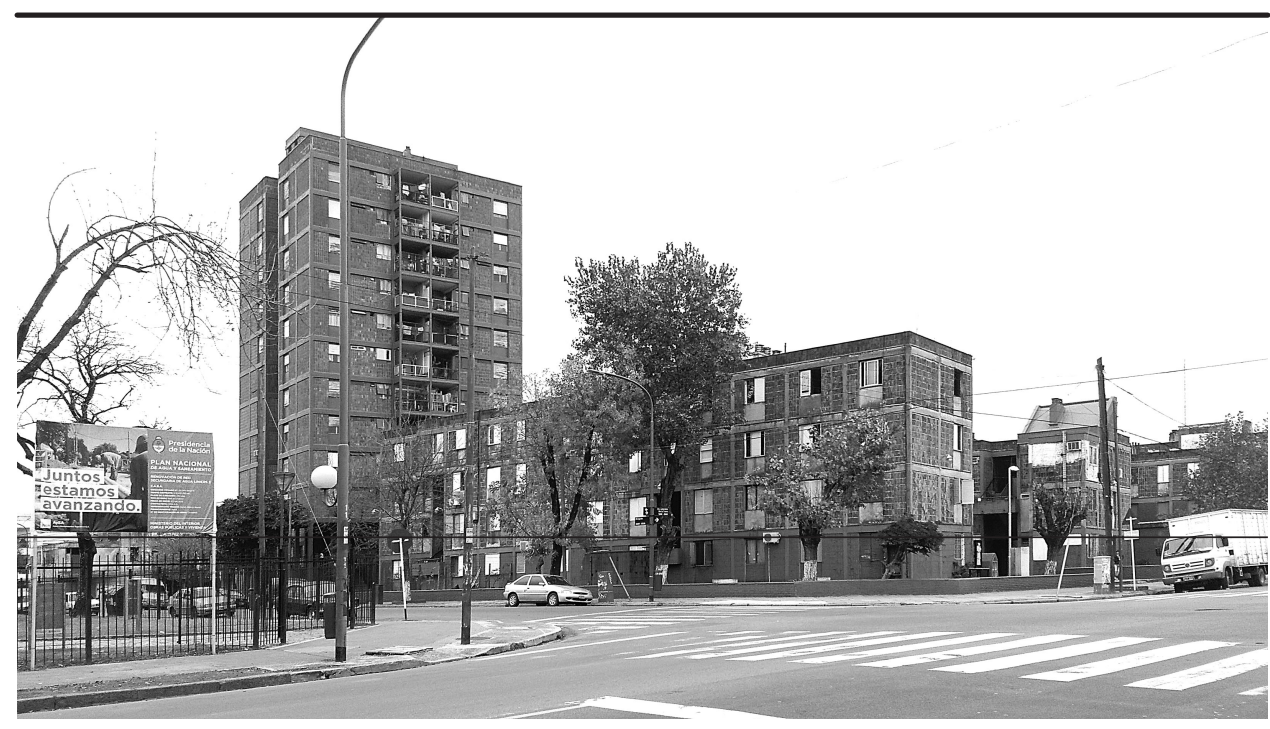

Fuente: Fotografía tomada por autora. 2017.

FIGURA 2. Barrio Justo Suárez: plano de localización en el marco de la ciudad

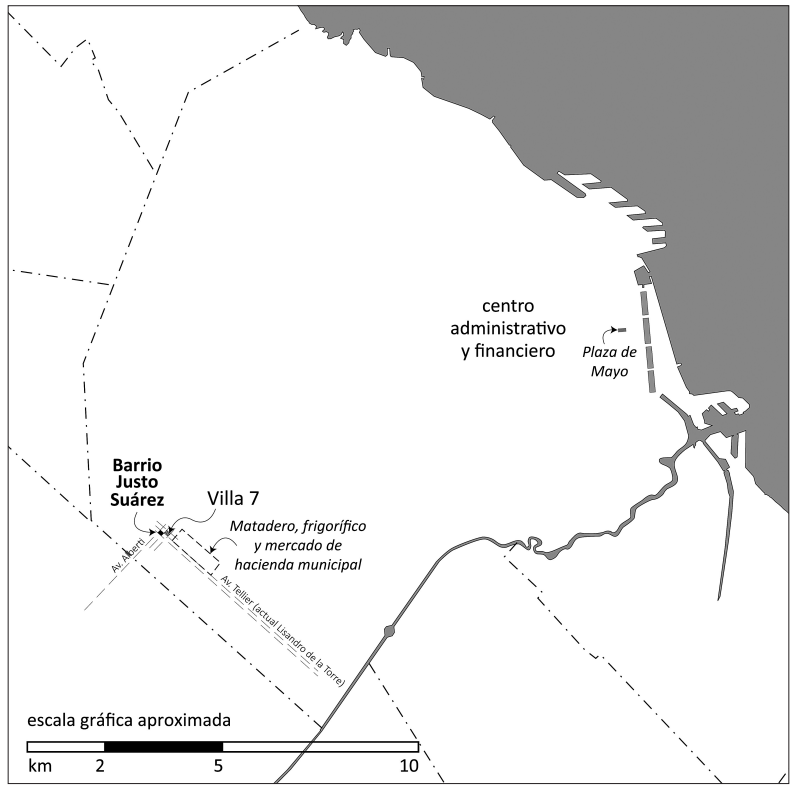

Fuente: Trazado por la autora. 


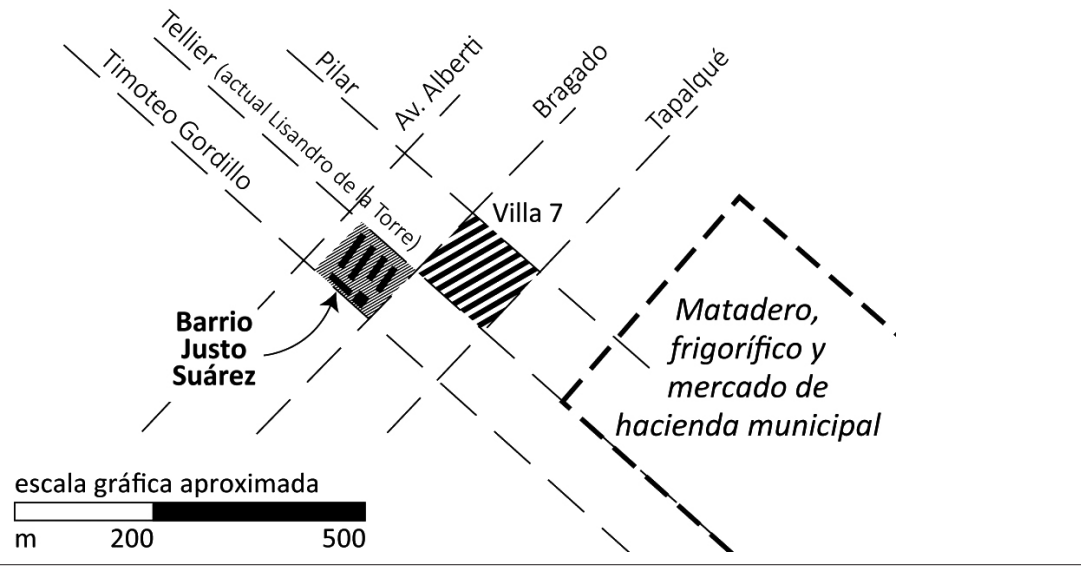

Fuente: Trazado por la autora.

y planificadorxs sino también habitantes de urbanizaciones informales interesadxs en replicar el proceso), así como las razones por las cuales se ha vuelto un referente en el debate sobre participación vecinal en Buenos Aires, responden al encuentro de tres aspectos.

En primer lugar, el Plan Piloto de Realojamiento de Villa 7 revistió un carácter excepcional en lo que se refiere a la perspectiva estatal respecto a villas miseria (el nombre local para urbanizaciones informales en Buenos Aires) no solo porque se propuso brindar unidades habitacionales en el mismo terreno en que la villa estaba ubicada (o en su defecto en el terreno disponible más cercano) sino también, y especialmente, por el hecho de que la participación popular fue concebida como el elemento clave y protagónico del proceso. A este respecto cabe recordar que, en el contexto argentino, las áreas denominadas "villas" se distinguen de otras modalidades de hábitat popular tales como las subdivisiones o loteamientos por su irregularidad en la tenencia del suelo. Es decir, en las villas los habitantes no han comprado ni alquilado el suelo sino que simplemente lo han ocupado como respuesta a una situación de extrema necesidad. La vulnerabilidad material, entonces, se superpone en las villas a la vulnerabilidad jurídica, lo cual empuja necesariamente a lxs vecinxs villerxs a dialogar con el Estado dado que se encuentran bajo permanente amenaza de desalojo hasta en tanto se resuelvan sus situaciones de tenencia.

Hacia comienzos de la década de los setenta la perspectiva oficial respecto a las villas en Buenos Aires se basaba en la idea de la erradicación, es decir, el desalojo forzoso y el traslado a unidades habitacionales ofrecidas por organismos estatales. A esta propuesta se resistían lxs vecinxs villerxs, sus juntas vecinales y sus agrupa- 
ciones, ante lo cual el Estado se planteaba estrategias de cooptación e intervención de las mismas (Comisión Municipal de la Vivienda, 1966; Ziccardi, 1977). En el Plan para Villa 7, lxs profesionales a cargo no solamente consultaron a lxs villerxs respecto al proyecto y lxs invitaron a participar en su materialización, sino que se acercaron a trabajar en la villa en una rutina que posibilitaba el contacto cotidiano. Asimismo el sistema de pagos y cuotas fue consensuado entre lxs habitantes del barrio, el departamento municipal a cargo y el equipo interdisciplinario liderado por Cedrón y Compagnucci.

En segundo lugar, si bien excepcional como obra construida y como aproximación estatal a la problemática de las villas, el Plan Piloto de Realojamiento de Villa 7 dio cuerpo a una serie de ideas sobre intervención popular en el campo de la vivienda social que venían desarrollándose desde algunos años antes. Eran conocidos, por ejemplo, los incipientes escritos de John F. C. Turner, quien basándose en su experiencia en las barriadas de Arequipa celebraba el aporte, la creatividad y el trabajo populares en la resolución de un problema inmediato de vivienda (Turner, 1963, 1965, 1967). El trabajo de Turner se enmarcaba a su vez en la discusión abierta por el Team X, un grupo de arquitectxs que desde Europa, con base en sus cuestionamientos internos a los CIAM (Congrès Internationaux d'Architecture Moderne, Congresos Internacionales de Arquitectura Moderna), desarrolló un rescate, si bien solo discursivo, de la arquitectura vernacular y el rol de lxs habitantes de los tenements victorianos (Smithson, 1968). Resultan particularmente relevantes las posiciones de Giancarlo di Carlo, miembro del Team X, respecto a la participación (Di Carlo, 2005 [1969]). En Argentina el interés en la participación popular se extendió dentro de la profesión arquitectónica hacia los mismos años en que el Plan Piloto para Villa 7 era producido, tal como puede verse en la producción editorial de revistas especializadas como Summa o Nuestra Arquitectura (Summa, 1971b; Summa, 1974; Nuestra Arquitectura, 1973a; Nuestra Arquitectura, 1973b). El Plan Piloto fue pionero en el abordaje de estas temáticas, y asimismo protagónico en estas publicaciones.

En los años inmediatamente posteriores al Plan Piloto, los intereses conceptuales predominantes en el debate arquitectónico argentino se desplazaron de la discusión sobre la arquitectura de sistemas, de matriz tecnoutópica, a la discusión sobre el rol del usuario y la participación popular en el diseño bajo una perspectiva de radicalización política. Surgió entonces un creciente interés en el desarrollo de tecnologías constructivas autoconstruíbles en el que las tipologías desarrolladas para el Plan Piloto tuvieron asimismo fuerte influencia. Figuras como la de Fermín Estrella jugaron un rol central en esta transición, asimismo extendiendo el debate sobre tecnologías basadas en la construcción popular y local hasta entrada la década de los ochenta (Estrella, 1984; Aliata, 2004). A lo largo de los años setenta y ochenta, la investigación sobre tecnologías simples y autocontrucción siguió desa- 
rrollándose de la mano, entre otros, del Centro Experimental de la Vivienda Económica, creado en Córdoba por Horacio Berretta en 1967 (Berretta, Álvarez, Aslan, Garino, Sartorio \& Ursini, 1966; Berretta, Massuh, Bosio de Buthet \& Pipa, 1979), o en el Instituto de Investigación y Desarrollo de la Vivienda (Universidad Nacional del Nordeste, Chaco), de la mano de Victor Pelli (Pelli, 1974, 2006).

En cuanto a antecedentes directos, en lo que se refiere a participación popular en proyectos construidos, el Plan Piloto reconocía como central a la iniciativa Asistencia Técnica, Esfuerzo Propio y Ayuda Mutua (atepam), iniciada por el Instituto de la Vivienda de la Provincia de Buenos Aires en 1962 bajo el Plan de Viviendas Populares del gobierno de Oscar Alende, con la que algunos integrantes del Equipo Técnico habían tomado contacto a través de Hilario Zalba (Provincia de Buenos Aires, 1962; Longoni, Molteni, Galcerán \& Fonseca, 2011, pp. 5-9; Barrios, 2011, pp. 34-35; Ricchezza, 2002; Azzarri, 2011). Compagnucci habría asimismo tomado en cuenta la posibilidad de la autoconstrucción al definir tecnologías constructivas para su proyecto de viviendas El Saladero en Bahía Blanca (Summa, 1971a). A nivel proyectual, un antecedente importante del Plan Piloto estaba representado por el proyecto de Wladimiro Acosta y equipo para la villa en Isla Maciel (Buenos Aires, partido de Avellaneda), desarrollado durante la segunda mitad de la década de los cincuenta y no construido (Acosta, 1967; Gaite, 2007, pp. 220-235). Pese a no estar centrado en la participación, el proyecto de Acosta constituía una referencia importante como intento de un equipo arquitectónico de comprender una problemática social en profundidad, y diseñar en consecuencia. Se encontraba, en efecto, enmarcado en la labor interdisciplinaria desarrollada en Maciel por el Departamento de Extensión de la Universidad de Buenos Aires. El Plan Piloto no solo tomaba inspiración proyectual del diseño de Acosta, por ejemplo en referencia a las tipologías de vivienda o las expansiones propuestas (figuras 4-6), sino que retomaba también la naturaleza interdisciplinaria del proceso de elaboración de ideas (Trama, 1982; Barrios, 2011, p. 119).

Por otro lado, es interesante destacar que el rol de la participación popular se discutía con creciente atención en el marco de los organismos interamericanos. La autoconstrucción asistida (me refiero en este caso a programas de ayuda mutua; en inglés self-help) había despertado interés en el Consejo Interamericano Económico y Social de la Organización de los Estados Americanos (CIEs/oeA) desde mediados de la década de los cincuenta, y era discutida crecientemente en los encuentros multinacionales organizados por este. La discusión sobre autoconstrucción asistida en este contexto sirvió de base para las políticas de la Alianza para el Progreso, la cual, a través de la Agencia de los Estados Unidos para el Desarrollo Internacional (United States Agency for International Development, Us-AID), financió parcialmente el programa atepam (Ministerio de Obras Públicas, 2013, p. 12; Taffet, 2007, pp. 29-39). 
FIGURA 4. Ejemplo de diseño en planta de dos unidades de vivienda de tiras bajas en Barrio Justo Suárez

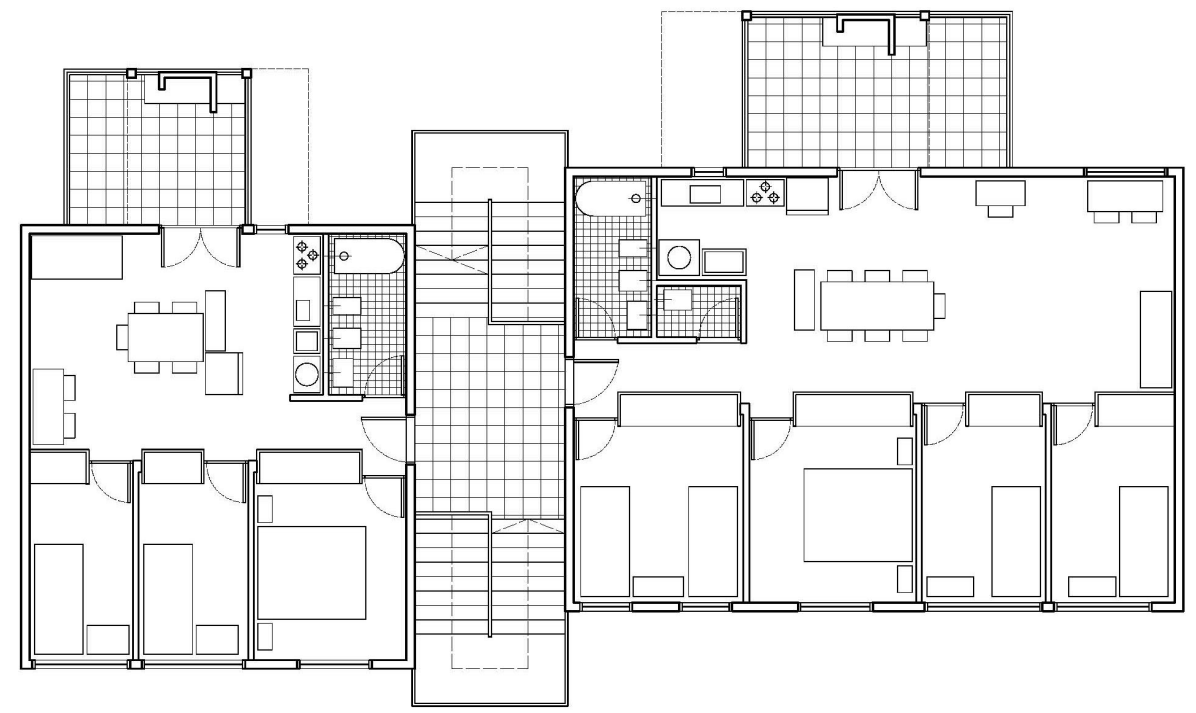

Fuente: Calcado por la autora del original en publicación Trama (1982)

Barrio Justo Suárez: Plan Piloto Realojamiento Villa 7 (3), 10-20.

FIGURA 5. Barrio Justo Suárez: acercamiento a dormitorio y terrazas; se aprecian también paneles de ladrillo autoconstruidos

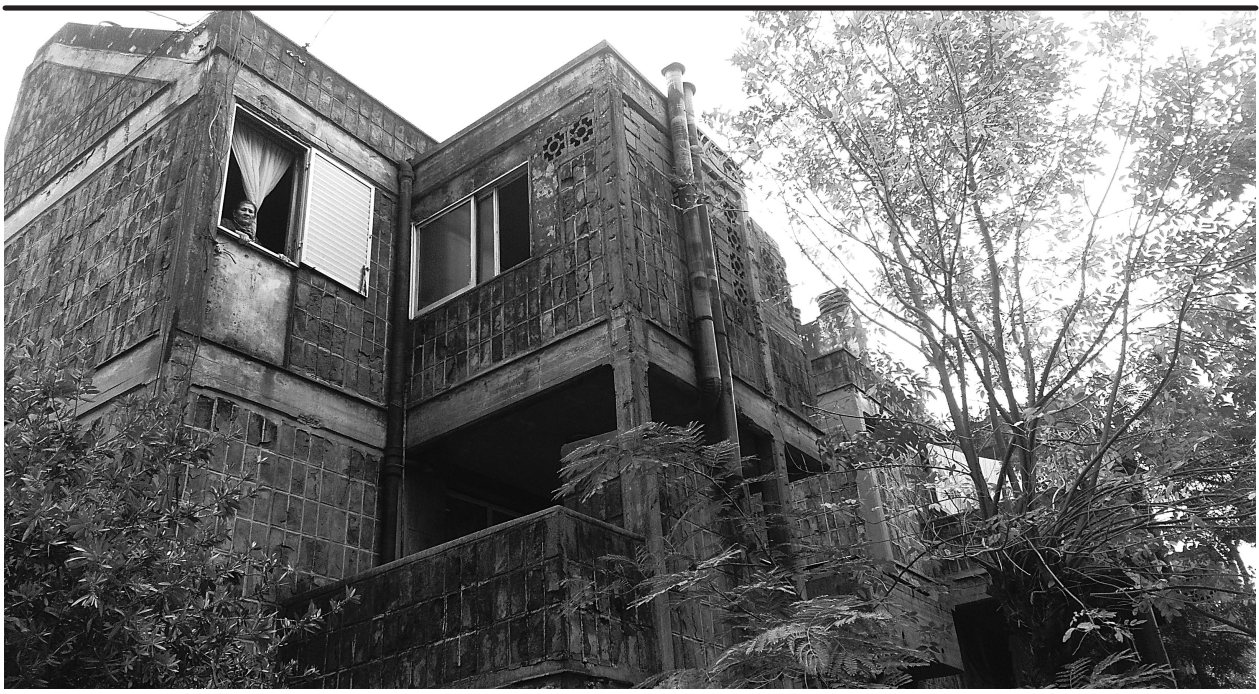

Fuente: Fotografía tomada por la autora, 2017. 
Como tercer aspecto que destacar, precisamente al recoger la importancia de la participación popular como motor central del cambio social, el Plan Piloto materializó, en el campo de la vivienda, reclamos generales de la población villera. El Plan Piloto, en efecto, reflejó un contexto particular de movilización política en el cual hizo propias tanto las demandas sostenidas por las comisiones vecinales locales como aquellas de organizaciones nacionales como el Frente Villero Peronista para la Liberación y el Movimiento Villero Peronista (El Descamisado, 1973b; Ce-

FIGURA 6. Barrio Justo

Suárez: acercamiento a dormitorio y terrazas; se aprecian también paneles de ladrillo autoconstruidos

Fuente: Fotografía tomada por la autora, 2017.

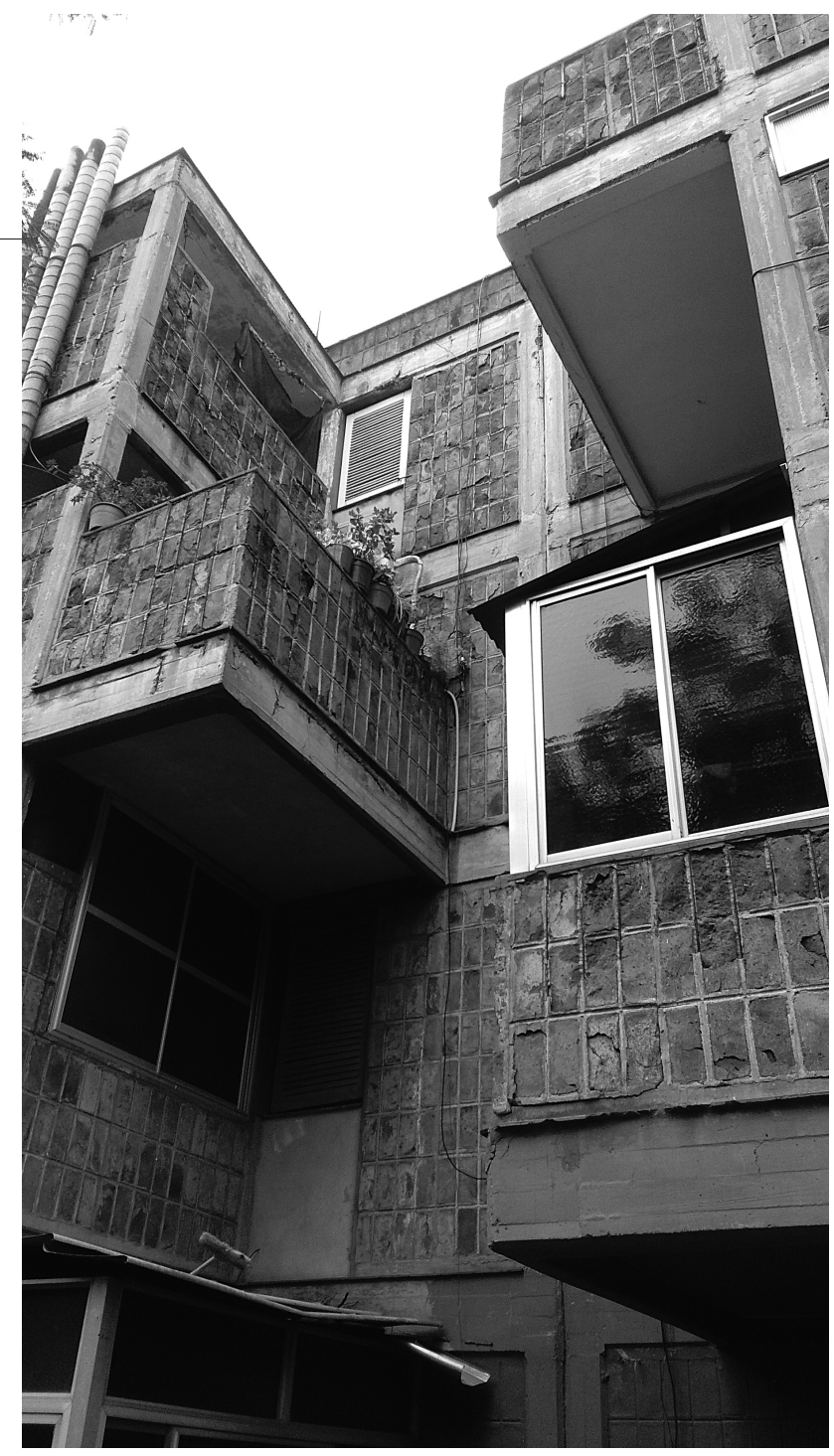


drón, 2000; Ziccardi, 1977, 1984; Dávolos et al., 1987). Los integrantes del Equipo Técnico, y en particular Osvaldo Cedrón, estaban al tanto de estos reclamos y estas luchas a través de su militancia política desde el peronismo de izquierda, y asimismo familiarizadxs con el trabajo cotidiano en barrios.

La incorporación de estos reclamos al proyecto arquitectónico había sido facilitada por la formación de grado recibida por Cedrón, Compagnucci e integrantes del equipo técnico tales como Ana Azzarri, Sara Fortuna, Eva Binder, Vicente del Hoyo y Hugo Santella en la Universidad de La Plata. En efecto, desde los años cincuenta, docentes como Hilario Zalba o Jorge Vivanco en el Instituto de Arquitectura y Urbanismo de la Universidad Nacional de Tucumán, primero, y en el Departamento de Arquitectura y Urbanismo de la Universidad Nacional de La Plata, después, habían comenzado a hacer hincapié en la importancia del acercamiento de la enseñanza de la arquitectura a los problemas sociales. Más adelante la propuesta de Zalba y Vivanco sería continuada en la ya Facultad de Arquitectura y Urbanismo de La Plata por Juan Molina y Vedia y Marcos Winograd (Longoni, Galcerán, Molteni, Pérez, Carranza, Fonseca \& Bottega, 2009; Carranza, 2010b). Estas ideas se discutían también en encuentros internacionales tales como los congresos de la Unión Internacional de Arquitectos.

Atendiendo a este contexto y dichos logros, cabe destacar que el Plan Piloto de Realojamiento de Villa 7 dio nuevo impulso a un debate sobre participación popular que aún se encuentra abierto. ¿Quiénes participan? ¿En qué participan (y en qué no)? ¿Quiénes se benefician en el proceso? Autores teóricos como Turner o Giancarlo di Carlo, en los años sesenta, o como Victor Pelli y Jeremy Till, hoy día, hacen hincapié en la importancia de la creatividad popular para la generación de la vivienda y la transformación urbana (Turner, 1963, 1965, 1967; Di Carlo, 2005 [1969]; Pelli, 2006; Till, 2005). En la práctica profesional, estudios como Elemental, de Alejandro Aravena, colocan el aporte del usuario al centro de su discurso (Aravena \& Iacobelli, 2012). Al mismo tiempo, la celebración de la autoconstrucción como solución al problema de la vivienda ha sido cuestionada por autores como Emilio Pradilla o Rod Burgess, quienes discutían con Turner en los años setenta y ochenta motivados por la preocupación de que la contribución popular sirviera de excusa para la retracción del Estado, llevando así a la sobreexplotación de la fuerza de trabajo de los usuarios (Burgess, 1978; Pradilla, 1982). Sin embargo, apoyo estatal y producción popular del hábitat no son necesariamente antagónicos, tal como la experiencia de realojamiento de Villa 7 nos muestra, aunque cabe destacar que su rol en el proyecto dependerá de las concepciones políticas que sirvan de sustento al mismo. Este artículo revisará primero el contexto de la perspectiva estatal en el que el Plan para Villa 7 se insertaba, para luego analizar el debate sobre autoconstrucción y participación política del que se nutría, finalizando por revisar su repercusión en ámbitos contemporáneos y en el largo plazo. 


\section{Contexto: perspectivas oficiales y el predominio de la idea de erradicación}

El Plan Piloto de Realojamiento fue iniciado en 1971 en Buenos Aires, Argentina, en el contexto del programa Gran Acuerdo Nacional y de la creciente ola de movilización popular que había comenzado con la protesta obrero-estudiantil denominada Cordobazo; y fue finalizado en 1975, durante el mandato de María Estela Martínez de Perón, cuando los asesinatos de Alberto Chejolán y Carlos Mugica, en un marco de represión también creciente, habían ya en gran medida erosionado la movilización de la población villera (El Descamisado, 1974; Ziccardi, 1984; Romero, 2012). Chejolán y Mugica eran figuras centrales en la Villa 31; el primero un residente villero baleado durante una movilización contra la erradicación de la villa, y el segundo un sacerdote ampliamente reconocido. La Villa 31, a su vez, era simbólica en Buenos Aires en cuanto a la lucha por los derechos de lxs vecinxs de urbanizaciones informales. Estos cuatro años, entonces, condensan una transformación fundamental para la interrelación entre vecinxs, profesionales y oficinas estatales, en la que se pasa de la tensión entre un paradigma de erradicación y su resistencia por parte de la población villera a la emergencia gradual de la noción de participación popular y diálogo proyectual, y finalmente a una clausura abrupta de estas experiencias en Argentina, aunque no así del debate.

Como hemos notado más arriba, el Plan Piloto para Villa 7 se insertó dentro de una perspectiva estatal que en referencia a las villas era la de la erradicación. Para ser precisxs, no es que esta perspectiva estatal fuera la única, ni que las mejoras in situ previamente no existieran. Desde fines de la década de los cuarenta, bajo los gobiernos de Juan Domingo Perón, Arturo Frondizi y Arturo Illia, diversas reparticiones proveyeron materiales y apoyo gratuito en iniciativas puntuales donde vecinxs y comisiones vecinales villeras aportaban la mano de obra, también gratuita, y que habían sido claves para la mejora de la habitabilidad a corto plazo de las villas (Massidda, en prensa). A nivel general, sin embargo, los programas de gran escala que se proponían intervenir en villas habían hasta entonces consistido en iniciativas dirigidas a eliminarlas físicamente, trasladando sus habitantes a unidades habitacionales en complejos construidos para ese fin por el Estado, o en algunos casos a soluciones habitacionales también precarias. Ejemplos de planes estatales de erradicación de villas habían sido el Plan de Emergencia (Comisión Nacional de la Vivienda, 1956), concebido con alcance nacional en 1956 pero puesto en práctica solo en el Área Metropolitana de Buenos Aires; el Plan Piloto para Erradicación de Villas de Emergencia, de aplicación puntual en tres villas de Buenos Aires (Comisión Municipal de la Vivienda, 1966), y el Plan de Erradicación de Villas de Emergencia, también operando en el Área Metropolitana de Buenos Aires (Ministerio de Bienestar Social, 1968). Tal como ha ocurrido en otras ciudades, la efectividad de las soluciones habitacionales propuestas por estas operatorias ha sido puesta en 
cuestión en varios casos, dado que se perciben problemas de costos demasiado elevados para residentes de recursos mínimos, que habrían dificultado el acceso efectivo a las unidades por parte de familias villeras; ubicaciones alejadas de las fuentes de trabajo, o problemas con las adjudicaciones tales como la falta de transparencia o el hecho de que las unidades definitivas prometidas no fueran finalmente otorgadas (Nuestra Palabra, 1963a; El Descamisado, 1973a; Yujnovsky, 1984, pp. 101-103 y 166-169; Blaustein, 2001, pp. 33-37; Massidda, 2012).

Planes de erradicación como los citados partían de una concepción de lxs habitantes villerxs como indolentes y poco productivxs, razón por la cual se lxs responsabilizaba por su propia pobreza y por las condiciones de precariedad de sus barrios (Ratier, 1971; Camelli \& Snitcofsky, 2012; Massidda, 2012). Además, subyacía a los planes la idea de que lxs habitantes villerxs eran portadorxs de pautas culturales ajenas al ámbito urbano. En el Plan de Emergencia, por ejemplo, se insiste en frases como "bajo nivel cultural" o "indiferencia ante el problema de la vivienda insalubre, inadaptación a la vida en comunidad, carencia de ambición y sentido de la responsabilidad etc.", para explicar el surgimiento y la permanencia de las villas (Comisión Nacional de la Vivienda, 1956, pp. 43-44). Sin embargo, tal como el resto de las fuentes históricas muestran, incluyendo los censos del propio Plan de Emergencia, la gran mayoría de residentes villerxs en las décadas de los cincuenta y sesenta se encontraba empleada y habitaba las villas por una cuestión de necesidad económica, constituyéndose además en comisiones vecinales para la mejora de los espacios barriales. Esto cobrará especial relevancia en relación con el impacto que producirá la propuesta para Villa 7 al interno de la Comisión Municipal de la Vivienda (CMv), transformando la mirada de muchxs de sus empleadxs (Dávolos et al., 1987). En este marco, naturalmente una intervención centrada en la participación popular como la llevada a la CMV por Cedrón, Compagnucci y el equipo representaba una innovación de fondo para las iniciativas municipales porteñas. Con posterioridad a la finalización del Plan Piloto para Villa 7, el gobierno del Proceso de Reorganización Nacional lanzó operatorias de desalojo compulsivo de villas en el ámbito de la Ciudad de Buenos Aires en el marco de un brutal terrorismo de Estado (Oszlak, 1991; Blaustein, 2001).

\section{Los debates sobre autoconstrucción y el rol del usuario}

La perspectiva con la que el Equipo Técnico se aproximó al Plan de Realojamiento para Villa 7 estaba enmarcada en el debate que en ese entonces surgía en torno al rol de los usuarios para la construcción de su vivienda. Por un lado, tal como hemos enfatizado, el interés en el rol de lxs usuarixs para la producción de su hábitat se encontraba en emergencia desde los años cuarenta en el contexto de iniciativas multinacionales interamericanas; y experimentaba creciente protagonismo en la 
profesión arquitectónica durante los años sesenta, desde el marco abierto por el Team X una década atrás hasta la producción teórica de Turner y un contexto latinoamericano en el cual la discusión, finalmente, se expandiría y complejizaría ampliamente. En efecto, aunque el Team X no planteaba la noción de participación popular tal como hoy día la entendemos, sus cuestionamientos abrieron un campo de posibilidad para el planteo de tales ideas por Giancarlo di Carlo, y asimismo para su articulación, y experimentación práctica, en Latinoamérica (Blundell Jones, Petrescu \& Till, 2005). Las formaciones de los miembros del equipo liderado por Cedrón y Compagnucci se habían visto influidas por este escenario y asimismo, de modo crucial, por la militancia política inserta en el contexto social y político de la Argentina de finales de la década de los sesenta.

Pueden distinguirse dos aproximaciones principales diferentes de la idea de participación del usuario en la producción del hábitat. Por un lado encontramos la idea de participación entendida como la acción de tomar parte en la construcción específicamente, actuando como mano de obra en proyectos donde las decisiones proyectuales y financieras han sido tomadas de antemano. Este es el marco de los proyectos de ayuda mutua tales como ATEPAM y de aquellos que venían discutiéndose en el marco de agencias internacionales especializadas desde los años cincuenta. Dichas perspectivas estaban insertas en un contexto político internacional en el que los Estados Unidos buscaban contener la preocupación de los países latinoamericanos por sus propias situaciones de desigualdad y evitar así el interés que en el seno de estos países despertaban de manera creciente propuestas centradas en cambios sociales profundos, especialmente luego de la Revolución Cubana (Cabot, 1954; Selser, 1964; Taffet, 2007). Ya en la década de los cuarenta, un organismo norteamericano, la Junta de Planificación de Puerto Rico, había ensayado modalidades de asistencia estatal en las que departamentos gubernamentales compraban lotes no urbanizados, los proveían de servicios y los ofrecían en arriendo o venta a familias de bajos ingresos que construirían sus viviendas allí (Inter-American Economic and Social Council, 1954, p. 56). ${ }^{4}$ Las premisas de estos programas serían retomadas en los encuentros organizados por el CIEs/OEA, y servirían de antecedente asimismo a las elaboradas por John Turner y retomadas por el programa PREVI (Lima, Perú), de gran influencia sobre el debate arquitectónico (Ballent, 2004; Gorelik, 2014). La autoconstrucción asistida por el Estado había sido también central para la labor del Centro Inter-Americano de la Vivienda (CInVa), creado en 1950 y puesto en funcionamiento en 1952 por el CIES/OEA.

Existe también una versión en castellano de este documento, de título Problemas de la vivienda de interés social (Consejo Interamericano Económico y Social, Washington D.C., Unión Panamericana, 1954), que sin embargo no es idéntica. Por ejemplo, en dicha versión no se incluyen las referencias a los programas self-help en Puerto Rico. En el presente artículo, por consiguiente, será citada la versión en idioma inglés. 
En 1954, el mismo CIEs/oea nombra una Comisión Ad Hoc para el Estudio de la Vivienda, cuyo informe sobre la situación de la vivienda popular en Latinoamérica se aprobaría en la Décima Conferencia Interamericana (Caracas, 1954). La Comisión Ad Hoc se concebía a sí misma como un agente técnico especializado cuya intervención no podía ni debía transformar problemas de índole social estructural (Inter-American Economic and Social Council, 1954, pp. 50-51). En otras palabras, aun notando el modo en que los niveles de desigualdad que aquejaban a las regiones latinoamericanas ponían a la vivienda fuera del alcance de buena parte de la población, la Comisión Ad Hoc trazaba un límite entre los problemas urbano-habitacionales y los de índole social y política, declarándose incapacitada para abordar los segundos y proponiendo que lxs profesionales expertxs en vivienda se abocaran exclusivamente a los primeros. Una perspectiva similar subyace a la labor de la Primer Reunión Técnica Inter-Americana de Vivienda y Planeamiento (Bogotá, 1956) (Unión Panamericana, 1958), y en menor medida a la de la Segunda Reunión Técnica Interamericana en Vivienda y Planeamiento (Huampaní, 1958) (Consejo Interamericano Económico y Social, 1959). Cabe destacar, entonces, que el aporte ofrecido por estas organizaciones en relación con la participación popular implicaba la permanencia del status quo en términos estructurales.

Algunos años después y desde una posición similar, luego de la Revolución Cubana, la Alianza para el Progreso sería lanzada como un programa de ayuda financiera a Latinoamérica destinado a contener el avance comunista (Taffet, 2007; Selser, 1964). En la Argentina, la Alianza para el Progreso cofinanció programas de vivienda como el ATEPAM o urbanos como el Parque Almirante Brown, encarado por la Municipalidad de la Ciudad de Buenos Aires (Provincia de Buenos Aires, 1962; Ministerio de Obras Públicas, 2013; Comisión Municipal de la Vivienda, 1965). Es interesante notar que, a pesar de que el contacto con la iniciativa ATEPAM marcó fuertemente la formación de lxs arquitectos participantes en el Plan Piloto en lo que se refiere a los aspectos concretos de la autoconstrucción asistida, su perspectiva respecto al rol político y social de la participación sería notablemente distinta.

Desde otra perspectiva, entonces, en ámbitos como el de la Universidad Nacional de La Plata, la participación popular era abordada en relación con su potencial de transformar radicalmente la estructura social y económica. Osvaldo Cedrón y el Equipo Técnico de Villa 7, formadxs en este contexto, concebían el significado del protagonismo del pueblo en la definición de la propia vivienda como un motor de cambio social. A nivel internacional, el interés creciente sobre el rol social del arquitecto en el marco de la disciplina arquitectónica se manifestaba en iniciativas como el Séptimo Congreso Internacional de la Unión Internacional de Arquitectos (UiA; La Habana, 1963), que recibió la visita de una delegación argentina compuesta, entre otrxs, por Azzarri, Vivanco y Molina y Vedia; o el Décimo Congreso de la UIA 
(Buenos Aires, 1969), precedido por un encuentro estudiantil donde la delegación de La Plata jugó un rol destacado (Carranza, 2014, pp. 43-44, 2010a, pp. 20-21). En el Séptimo Congreso se planteó con claridad una concepción de la profesión arquitectónica en la cual la excelencia profesional estaba intrínsecamente ligada al compromiso político, cristalizada en el discurso de Ernesto Guevara: "quien pretenda decir que solamente un técnico, un arquitecto, un médico, un ingeniero, un científico de cualquier clase está para trabajar con sus instrumentos, solamente en su rama específica, mientras su pueblo muere de hambre, o se mata en la lucha [...] [n]o es apolítico, es político pero contrario a los movimientos de liberación" (Guevara, 1985 [1977], p. 116, citado en Carranza, 2014, p. 45). Asimismo, cabe destacar la importancia de espacios informales de debate estudiantil vitales para la formación de lxs diseñadorxs del Plan Piloto durante los años sesenta (Cedrón, 2000; Longoni, Galcerán, Molteni, Pérez, Carranza, Fonseca \& Bottega, 2009, p. 15; Barrios, 2011,pp. 84-89).

Sin embargo, quizás los ámbitos que más marcaron la perspectiva de lxs profesionales involucradxs en Villa 7 hayan sido los de la militancia política, en el marco de la proscripción del peronismo y de una creciente movilización popular en busca de mejoras en las condiciones sociales. Argentina transitaba el final de la década de los sesenta bajo una dictadura militar autodenominada Revolución Argentina, liderada entonces por Juan Carlos Onganía; bajo un creciente descontento popular motivado por la represión ejercida por el gobierno, las amenazas impuestas a los derechos laborales, y la permanencia de la proscripción del peronismo, partido mayoritario. Este descontento había encontrado su primera expresión en el Cordobazo, una protesta masiva sostenida durante días por obreros y estudiantes en la ciudad de Córdoba, y había luego entrado en una espiral creciente que abarcaba desde la masificación de agrupaciones radicalizadas (un ejemplo es la Juventud Peronista) y agrupaciones de base (tales como los movimientos villeros) hasta la emergencia y expansión de la lucha armada (Tarcus, 2008; Gillespie, 1982).

En el contexto citado, la experiencia en barrios a través de ámbitos de militancia peronista había dado a Cedrón y otros miembros del equipo un espacio de maduración de ideas de cambio social que luego sería volcado en la realización del proyecto para Villa 7. En efecto, las organizaciones villeras de Buenos Aires venían desde los años sesenta planteando la necesidad del apoyo estatal a mejoras en villas, enfatizando la importancia de permanecer en las cercanías de sus espacios de trabajo y reclamando que, de ejecutarse algún plan de desalojo y traslado, las viviendas ofrecidas fueran de calidad aceptable, con cuotas accesibles y adjudicación transparente. Reclamos como estos habían sido recogidos originalmente por la Federación de Villas y Barrios de Emergencia durante los años sesenta, y reiterados en 1973 por el Frente Villero Peronista de Liberación y de modo indirecto por el Movimiento Villero Peronista (Nuestra Palabra, 1963b; Ziccardi, 1984; Snitcofsky, 2011; Camelli, 2013). 


\section{Participación, ayuda mutua y agencia}

Podemos leer el contraste entre las perspectivas sobre el rol del usuario materializadas en Villa 7 y aquellas sostenidas, por ejemplo, en reportes como el de la Comisión Ad Hoc, a la luz del diferente rol que en ambas ocupa la agencia del usuario, o el balance de agencias atribuidas a los diferentes actores intervinientes (vecinxs, profesionales, dependencias estatales). Entendemos aquí "agencia" como la capacidad de una entidad o un individuo para transformar un estado de cosas (Giddens, 1984; Latour, 2005; Awan, Schneider \& Till, 2013). La noción de agencia ha sido ampliamente discutida en las ciencias sociales. Una teorización como la de Giddens, por ejemplo, se concentra en definir el alcance de la agencia (concebida como individual y humana) en relación con la estructura social. De acuerdo con Giddens la capacidad de un individuo para transformar el entorno que lx rodea se desarrolla simultáneamente de manera independiente y condicionada por su entorno o por la estructura social, política y económica en la que se inserta. Por un lado, puede conceptualizarse el accionar de un individuo como condicionado por una estructura económica, política, urbana o social: en una teorización de este tipo el libre albedrío queda reducido a un mínimo, y es la estructura que determina los procesos. Por otra parte, la agencia individual puede pensarse como generadora original de dichos procesos, en cuyo caso la estructura surge de la sumatoria de los accionares individuales. Buscando trascender esta dicotomía entre estructura y agencia, Giddens se interesa en la interrelación entre ambas, proponiendo que la agencia es efectivamente la habilidad de un individuo de transformar el entorno que lx rodea, actuando de manera independiente de (aunque inevitablemente condicionada por) las estructuras sociales (Giddens, 1984, pp. xxii-xxiii, 8-14, 25).

Giddens, simultáneamente, incluye la condición de intencionalidad en la idea de agencia (según Giddens podemos hablar de agencia cuando se trata de una transformación intencional), perspectiva que ha sido ampliamente discutida por otrxs autorxs. De acuerdo con Bruno Latour, por ejemplo, la categoría de intencionalidad es irrelevante dado que entidades sin, en principio, capacidad reflexiva, generan transformaciones en su entorno también (Latour, 2005, pp. 70-72). Aquí Latour está en particular interesado en discutir la agencia de entidades inanimadas, comenzando por objetos cotidianos, lo cual excede el análisis en que profundizaremos en este artículo, enfocado en la agencia humana. Cuestionar la noción de intencionalidad y definir la agencia principalmente por su capacidad transformativa nos permite, sin embargo, indagar en su naturaleza y sus limitaciones en cuanto a práctica crítica. Para autorxs como Awan, Schneider y Till, por ejemplo, basados en la disciplina arquitectónica, la idea de agencia en términos de Giddens es agencia crítica, consiste en la capacidad de un agente de desprenderse de un estado de cosas y desarrollar una práctica innovadora (por ejemplo en arquitectura) (Awan et al., 2013). 
El motivo por el cual los análisis propuestos por Giddens y Awan, Schneider y Till nos interesan para el caso de Villa 7 refiere, entonces, a la riqueza con que la simultaneidad de autodeterminación y subordinación están pensadas. La noción de agencia es extremadamente útil para entender la diferencia planteada entre una concepción de participación que propone a la misma como parte de una transformación integral de la estructura política y otra que la limita al aporte de mano de obra, por parte de lxs usuarixs, y de asistencia técnica, por lxs profesionales involucradxs. En ambos casos tenemos una intervención que cambia un estado de cosas y es al mismo tiempo limitada por su contexto. La primera, sin embargo, se propone explícitamente subvertir ese contexto, o al menos podemos decir que maximiza su independencia y capacidad transformativa. La segunda, en cambio, propone cubrir una necesidad habitacional pero minimizando la agencia, la capacidad de accionar de lxs actorxs involucradxs.

Retomando el término "participación”, este se refiere a tomar parte, a involucrarse con una contribución individual a un estado de cosas (Diccionario de la lengua española, 2014). En el caso del Plan Piloto, la participación en el desarrollo del proyecto y la construcción fue pensada como un impulso, un potenciamiento, una celebración de la agencia de lxs vecinxs de Villa 7 entendida en todas las variantes que han sido mencionadas hasta este punto en este artículo: como actividad transformadora, como práctica crítica, como accionar que se desprende de un marco dado buscando cambiar un estado de cosas aun encontrándose necesariamente condicionado por ese marco que inevitablemente la contiene. En primer lugar, al participar, lxs residentes estaban produciendo un cambio (en sus situaciones habitacionales, en el diseño de las unidades de vivienda, en la dinámica del proceso), y simultáneamente operando dentro de condiciones externas (las impuestas por la naturaleza municipal del proyecto y su inserción en estructuras burocráticas estatales; por el hecho de que fuera coordinado por un equipo profesional; por sus presupuestos). A mayor escala, además, el Plan Piloto se consideraba a sí mismo como la faceta habitacional de un cambio social más profundo que tomaría lugar con el levantamiento de la proscripción al peronismo y la integración de los sectores populares en las decisiones de gobierno. Cabe aclarar que la transformación social de la que el Plan Piloto se consideraba parte no fue lograda sino cercenada en seco por la última dictadura militar en Argentina: lo que estoy analizando aquí, sin embargo, son las ideas que subyacían al Plan y a sus prácticas.

La agencia de lxs residentes en el Plan Piloto, en tanto posibilidad de cambio, se ve con particular claridad al comparar el Plan con proyectos como los ATEPAM. En proyectos de ayuda mutua lxs residentes o usuarixs no transformaban el proyecto o la tipología, ni influían en las decisiones: eran solo incorporadxs a un proceso constructivo que, de hecho, se habría realizado de igual modo si hubiera sido efectuado por personal contratado. De hecho, en el contexto de proyectos diseñados de 
antemano de modo centralizado, la agencia o práctica crítica de lxs vecinxs constructores hubiera tenido un efecto disruptivo. Puede decirse que, en casos como los de ayuda mutua, la participación es una participación sin agencia o donde la agencia de lxs vecinxs se ve notablemente restringida. No estoy con esto intentando minimizar la relevancia, los logros, la trayectoria ni las excelentes ideas y prácticas implicadas en proyectos de ayuda mutua, pero sí buscando clarificar que el término 'participación', aun usado tanto en ellos como en casos como el Plan Piloto, reviste implicancias totalmente distintas. El alcance que tuviera la incorporación o no de lxs residentes a las decisiones de proyecto en el caso de un plan de relocalización de familias villeras no solo afectaba el grado en el cual los resultados pudieran ser adecuados a las necesidades de las mismas, sino que también reflejaba una concepción política del rol del proyecto para la estructura social y urbana en general. En otras palabras, al incorporar y promover la agencia de lxs residentes en las decisiones que se fueran a tomar, el Plan Piloto respondía a la convicción de que un plan de relocalización habitacional no consistía solo en la resolución técnica de un problema de alojamiento sino que era parte de una discusión acerca de qué lugar correspondía a los grupos villeros en la sociedad; cuánto podían y debían estos, más allá de sus limitaciones económicas, decidir sobre su futuro; y de qué modo esto podría afectar y transformar al resto de la sociedad y los procesos urbanos.

Finalmente, el Plan Piloto en sí tuvo una capacidad transformadora, sobre todo si atendemos a sus repercusiones en su medio, por haber sido el primer proyecto destinado a villas que proponía no solo su relocalización en el área (en contraste con la erradicación y el traslado a la periferia urbana) sino también la integración de la agencia de lxs residentes. Tal como mencionamos, el Plan Piloto retomó una muy incipiente discusión sobre participación, le dio un fuerte impulso y se convirtió en estandarte de la misma para sus contemporáneos. En cuanto a tecnologías constructivas, los prototipos propuestos por la CMV en relación con este proyecto comenzaron a circular en revistas especializadas y fueron pioneros en la investigación sobre tipologías y sistemas constructivos destinados al hábitat popular en Argentina. En cuanto a las dinámicas de participación en sí, el Plan Piloto fue antecedente del sistema de mesas de trabajo que comisiones de otras villas propusieron a la CMV. Las mesas de trabajo consistían en espacios de debate sobre temas específicos (provisión de agua, sistemas de desagüe, salud y asistencia, etc.) que ponían en conversación a delegadxs villerxs con representantes municipales, con la intención de replicar el Plan Piloto en otras villas donde la mayor escala imposibilitaba el proceso exhaustivo de coproyecto que se había hecho en Villa 7 (Nuestra Arquitectura, 1973b, p. 21). Estas iniciativas se vieron truncadas por una creciente persecución a líderes villerxs a partir de 1974 y un nuevo golpe de estado en 1976. Finalmente, en cuanto a planes concretos para otras villas, el Plan Piloto fue antecedente directo del Proyecto de Radicación para la Villa 31, elaborado por la comisión vecinal en 
colaboración con arquitectos y sociólogos y retomando las ideas de permanencia en el barrio (Camelli \& Snitcofsky, 2016, p. 42). Podemos ver, entonces, que siendo un proyecto municipal, el Plan Piloto modificó radicalmente el estado de la cuestión de la intervención estatal en villas.

\section{La materialización del Plan Piloto: mejoras en Villa 7 y la construcción del Barrio Justo Suárez}

La perspectiva del equipo interdisciplinario liderado por los arquitectos Cedrón y Compagnucci se vio plasmada en la concepción y el desarrollo del Plan Piloto de Realojamiento en varios aspectos. El proyecto fue propuesto por el equipo a la Municipalidad de Buenos Aires, la cual lo aceptó otorgándole un presupuesto específico e insertándolo dentro de las incumbencias de la CMV, entidad municipal entonces a cargo del trabajo en villas (Trama, 1982; Dávolos et al., 1987; Ziccardi, 1977). Se eligió Villa 7 para implementar el programa piloto por su escala: al ser una villa pequeña, se facilitaría la labor participativa y el realojamiento antes de ser el Plan replicado en otros barrios. En efecto, la naturaleza "piloto" del plan era la de una primera implementación de un sistema extensible como solución habitacional.

El Plan Piloto comenzó por la consulta cotidiana con residentes, tanto a sus líderes como a las familias. El equipo de trabajo, de hecho, a pesar de haber sido asignado a oficinas en la CMv, localizadas en el centro de la ciudad, estableció como su espacio de trabajo la villa misma, facilitando así el contacto diario con lxs vecinxs y su accesibilidad para consultas (Barrios, 2011, pp. 90-95). A pedido de lxs vecinxs, se realizaron inicialmente mejoras en la villa, incluyendo una guardería y un sitio de reuniones vecinales (El Descamisado,1973b). Sin embargo, el propósito del Plan Piloto era el realojamiento de las familias en unidades de vivienda social que serían financiadas por la Municipalidad, co-construidas por residentes y contratistas y vendidas a sus ocupantes en cuotas al largo plazo. El barrio resultante sería llamado Justo Suárez, en honor al conocido boxeador argentino originario del barrio de Mataderos, donde tanto la villa como el terreno del nuevo conjunto se encontraban. En efecto, ante la imposibilidad de construir las nuevas viviendas en el lote mismo donde Villa 7 estaba asentada, que era la opción originalmente propuesta, se consiguió un terreno a menos de 200 metros del terreno original (figura 3). Esta posición no solo reconocía la importancia de la localización para lxs vecinxs por razones de trabajo sino también las redes de solidaridad entre familias construidas a lo largo del tiempo, las cuales jugaban un rol importante en relación con la capacidad de supervivencia y de cuidado mutuo cotidiano, así como de autoorganización. 
Tal como hemos mencionado, el diseño de estas unidades de vivienda se realizó en colaboración con lxs vecinxs, integrándolxs a todas las etapas proyectuales. A consecuencia de esto, las unidades de vivienda del Barrio Justo Suárez presentaron innovaciones en cuanto a su diseño -terrazas, cantidad de cuartos, intimidad- que contrastaban con los modelos más rígidos de los conjuntos de vivienda social de la época, dando cuenta de la efectividad del proceso de diseño participativo. Respecto a cantidad de cuartos, las unidades reflejaban los tamaños reales de las familias que iban a ser alojadas en vez de basarse en modelos abstractos de familia tipo, lo cual llevó a una variedad particularmente amplia de unidades. En cuanto a las expansiones, respondiendo a la preferencia de las familias villeras por las viviendas unifamiliares en planta baja, imposibles de materializar como tales dada la densidad requerida en el terreno, se buscó recrear el contacto con el cero en expansionesterraza con proporciones de patio (figuras 4-6). Respecto a la privacidad interna, en aras de dar a los ambientes interiores la mayor amplitud posible, se prescindió de circulaciones interiores que aseguraran la intimidad de los accesos a las habitaciones, dado que aquella y no esta última era la prioridad indicada por las familias (Trama, 1982; Barrios, 2011, pp. 120-131).

Por último, la perspectiva política del Equipo Técnico se percibe claramente en la importancia otorgada a las contrataciones formales de lxs vecinxs villerxs que participarían en la construcción, y en la búsqueda de generar soluciones tecnológicas que pudieran ser llevadas a cabo por mano de obra no especializada, in situ, en el intento de dar un primer paso para la gestación de empresas populares -o estatales, con protagonismo popular- de construcción. Lxs villerxs participantes en obra fueron contratados formalmente por la CMV a instancias del Equipo Técnico, con todas las cargas sociales. De este modo, puede leerse el Plan Piloto para Villa 7 como una respuesta anticipada a aquellas críticas dirigidas a los programas de autoconstrucción en los que se denunciaba la explotación de mano de obra que dichos programas, de no mediar los debidos recaudos, podían significar (Burgess, 1978; Pradilla, 1982). Sin negar la validez de estas críticas, podemos notar que la autoconstrucción no necesariamente implica explotación sino que esto es definido por las modalidades de contrato y en última instancia la voluntad política. Cabe recordar que la permanencia en el barrio, la participación, y en menor medida la capacidad de los programas de vivienda de proveer empleo a lxs residentes villerxs, constituían parte fundamental de los reclamos de los sectores villeros desde los años sesenta, y como tales habían sido recogidas por el Equipo Técnico ( $L a$ Hora, 1958; La Voz de las Villas, 1965, 1969, 1970a, 1970b). En relación con esto, los reclamos villeros de los años cincuenta y sesenta pueden leerse como modos de resistencia no solo a las condiciones concretas de precariedad habitacional y amenaza permanente de desalojo sino también al marco conceptual que planes estatales como el PE o el PEVE proponían, en el que los vecinos eran responsabilizados 
por sus propias condiciones de vida y no contaban con ningún tipo de voz. En este sentido, el Plan para Villa 7 puede interpretarse como una iniciativa que enarbola la bandera villera no solo desde el plano material sino también desde el simbólico.

\section{Proyectando una mirada al largo plazo}

La intención inicial de transformar al Plan Piloto para Villa 7 en una iniciativa pasible de ser replicada en otras villas y otros contextos se vio simultáneamente frustrada y realizada en el largo plazo. Frustrada porque, como es sabido, el cierre de ciclo respecto al contexto sociopolítico precipitó la clausura de los canales de protagonismo popular en la definición de ciudad y vivienda. Al mismo tiempo, consideramos realizada la vocación del Plan en tanto y en cuanto demostró la factibilidad de una propuesta capaz de integrar poder de decisión proyectual real de lxs vecinxs en forma conjunta con lxs profesionales, manteniendo los parámetros de costos, tiempos y calidad constructiva dentro de las magnitudes estipuladas. En forma contemporánea a su puesta en práctica, el Plan Piloto de Realojamiento trascendió las fronteras de Villa 7 mediante las mesas de trabajo, que institucionalizaron la modalidad propuesta por el equipo técnico en el ámbito de la CMV a través de un sistema de discusión y proyecto conjunto permanente con vecinas y vecinos villerxs, posibilitando así que la metodología del Plan se generalizara para otros asentamientos. La operativa de las mesas fue además discutida en el Primer Congreso Nacional de Vivienda Popular (Facultad de Arquitectura y Urbanismo, 1973), extendiéndose así el debate a la comunidad arquitectónica en general. Esto fue acompañado por la difusión del proyecto para el barrio Justo Suárez en revistas especializadas (Nuestra Arquitectura, 1973b; Summa, 1974). Asimismo, el Plan Piloto contribuyó a consolidar un cambio de perspectiva clave para gran parte del personal profesional y técnico que trabajaba en la cMv. En efecto, si bien fue diseñado por el equipo técnico antes de su incorporación a la Comisión, el Plan resonaba con inquietudes que miembros de la CMV venían por su parte albergando previamente respecto al modo de abordar la cuestión villera (Dávolos et al., 1987; Álvarez, 2014). Algunos años después, la experiencia en Villa 7 se constituyó como antecedente de las cooperativas de construcción surgidas a principios de los años ochenta (Bellardi \& De Paula, 1986, pp. 87-89).

El Plan Piloto se destaca hoy día, entonces, como una experiencia de diseño participativo única en su incorporación efectiva de lxs usuarixs. La frase "diseño participativo" se ha transformado desde los años setenta en ubicua, e incluso podría argumentarse trillada, empleada para designar procesos que van desde consulta pública hasta autoconstrucción asistida. En algunos contextos nacionales, por ejemplo, el carácter "participatorio" de los procesos de diseño urbano es un requeri- 
miento formal para efectuarlos, pero en muchos casos este se limita a la proporción de información a la comunidad afectada y la obtención de su consentimiento (Till, 2005). La experiencia de Villa 7 ha demostrado que, con una adecuada atención a los canales de participación de lxs vecinxs, su inclusión conjunta con lxs profesionales en las decisiones de cada etapa del proyecto (en otras palabras, su agencia), y la remuneración formal de sus trabajos en obra, toda experiencia de participación popular en la producción del hábitat podría implicar una articulación conjunta de los esfuerzos populares, técnicos y estatales. En otras palabras, en un debate que aún dista de encontrarse cerrado, la experiencia en Villa 7 perdura como una demostración de que creatividad popular e intervención estatal no son polos necesariamente antagónicos sino que (aunque sea inusual) pueden ser articulados mediante una cuidada propuesta interdisciplinaria sumada a voluntad política. En un contexto en el que aún buscamos respuestas a los problemas de déficit habitacional y pobreza urbana la reflexión sobre esta posibilidad de esfuerzo conjunto es más que necesaria.

\section{Referencias}

Acosta, W. (1967). Viviendas en Isla Maciel: memoria técnica. Summa, 10, 56-57.

Aliata, F. (2004). Sistemas (arquitectura de). En Aliata, F. \& Liernur, J. F. (eds.), Diccionario de arquitectura en la Argentina: estilos, obras, biografías, instituciones, ciudades (vol. S/Z, pp. 57-60). Buenos Aires: Clarín Arquitectura/AgEA.

Álvarez, M. (2014, 22 de julio). Entrevista por Adriana Laura Massidda.

Aravena, A. \& Iacobelli, A. (2012). Elemental: incremental housing and participatory design manual. Ostfildern: Hatje Cantz.

Awan, N., Schneider, T. \& Till, J. (2013). Spatial agency: other ways of doing architecture. Hoboken: Taylor and Francis.

Azzarri, A. (2011). Entrevista por Romina Barrios, reproducida en Barrios, R., Participación y hábitat popular. Análisis de una experiencia piloto: el Plan de Realojamiento de la Villa 7 en Mataderos, Ciudad de Buenos Aires, entre 1971 y 1975 (pp. 74-76). Tesis de maestría, Universidad de Buenos Aires. Buenos Aires, Argentina.

Ballent, A. (2004). Learning from Lima. Previ, Perú: habitar popular, vivienda masiva y debate arquitectónico, 1945-1970. Block, 6 (Tercer Mundo), 86-95.

Barrios, R. (2011). Participación y hábitat popular. Análisis de una experiencia piloto: el Plan de Realojamiento de la Villa 7 en Mataderos, Ciudad de Buenos Aires, entre 1971 y 1975. Tesis de maestría, Universidad de Buenos Aires. Buenos Aires, Argentina.

Basualdo, V. (ed.), La clase trabajadora argentina en el siglo xx: experiencias de lucha y organización. Buenos Aires: Cara o Ceca. 
Bellardi, M. \& De Paula, A. (1986). Villas miseria: origen, erradicación y respuestas populares. Buenos Aires: Centro Editor de América Latina.

Berretta, H., Álvarez Vicente, R., Aslan, J., Garino, J., Sartorio, A. \& Ursini, C. (1966). Viviendas para el desarrollo de una comunidad. Nuestra Arquitectura, 431, 39-47.

Berretta, H., Massuh, H., Bosio de Buthet, G. \& Pipa, D. (1979). Sistema Mas. Córdoba: Centro Experimental de la Vivienda Económica.

Blaustein, E. (2001). Prohibido vivir aquí: una historia de los planes de erradicación de villas de la última dictadura. Buenos Aires: Comisión Municipal de la Vivienda.

Blundell Jones, P., Petrescu, D. \& Till, J. (eds.) (2005). Architecture and participation. London: Spon Press.

Burgess, R. (1978). Petty commodity housing or dweller control? A critique of John Turner's views on housing policy. World Development, 6(9), 1105-1133.

Cabot (1954). Memorandum by the Assistant Secretary of State for Inter-American Affairs (Cabot) to the Secretary of State. Doc. 66, 362/1-1354. Recuperado de http://history. state.gov/historicaldocuments/frus1952-54v04/d66 [último acceso 11 de diciembre de 2016].

Camelli, E. (2013). Politicidad villera. El Movimiento Villero Peronista, 1973-1976. Tesis doctoral, Universidad de Buenos Aires. Buenos Aires, Argentina.

Camelli, E. \& Snitcofsky, V. (2012). La “villa” de Buenos Aires: génesis, construcciones y sentidos de un término. Café de las Ciudades, 121.

Camelli, E. \& Snitcofsky, V. (2016). Primer Plan de Radicación para la Villa 31. Un antecedente a la defensa del Derecho a la Ciudad en Buenos Aires (1972-1974). Quid 16, 6, 17-46.

Carranza, M. (2010a). Arquitectura, movimiento estudiantil y los espacios de la FAU-UNLP (1966-1973). En III Jornadas de Estudio y Reflexión sobre el Movimiento Estudiantil Argentino. La Plata: Universidad Nacional de La Plata.

Carranza, M. (2010b). Innovaciones en la enseñanza: el desembarco de los talleres verticales en arquitectura (1955-1966). En Echeverría, M. P. \& Vestfrid, P. (eds.), Tridecaedro: jóvenes investigadores en ciencias sociales de la UNLP (pp. 25-43). La Plata: Universidad Nacional de La Plata.

Carranza, M. (2014). Entrelazamientos. Cultura política y cultura del espacio en el vir Congreso Mundial de Arquitectos de la UIA, La Habana, Cuba, 1963. Registros, 10(11), 40-56.

Cedrón, O. (2000). Villa 7 - Plan Piloto de Realojamiento: balance de una experiencia. Revista de Arquitectura, 198, 108-111.

Comisión Municipal de la Vivienda (1965). Centro Urbano Integrado Parque Almirante Brown: Solicitud de préstamo al Banco Interamericano de Desarrollo (vol. 1). Buenos Aires: Municipalidad de la Ciudad de Buenos Aires. 
Comisión Municipal de la Vivienda (1966). Plan Piloto para Erradicación de Villas de Emergencia: Villas de Emergencia n 5-6-18. Buenos Aires: Municipalidad de la Ciudad de Buenos Aires.

Comisión Municipal de la Vivienda (1970). C.M.V. _ Villas de Emergencia. Buenos Aires: Municipalidad de la Ciudad de Buenos Aires.

Comisión Nacional de la Vivienda (1956). Plan de emergencia: informe elevado al Poder Ejecutivo Nacional. Buenos Aires: Ministerio de Trabajo y Previsión.

Consejo Interamericano Económico y Social (1959). Segunda Reunión Técnica Interamericana en Vivienda y Planeamiento: Informe final. Washington, D.C.: Pan-American Union.

Dávolos, P., Jabbaz, M. \& Molina, E. (1987). Movimiento villero y estado (1966-1976). Buenos Aires: Centro Editor de América Latina.

Diccionario de la lengua española (2014). Participar (23ª ed.). Real Academia Española. Consultado en http://dle.rae.es/?id=S09ab8h [último acceso 11 de diciembre de 2016].

Di Carlo, G. (2005). Architecture's public. Conferencia dictada en 1969. Reproducida en Blundell Jones, P., Petrescu, D. \& Till, J. (eds.), Architecture and participation (pp. 3-22). London: Spon Press.

Echeverría, M. P. \& Vestfrid, P. (eds.), Tridecaedro: jóvenes investigadores en ciencias sociales de la UNLP. La Plata: Universidad Nacional de La Plata.

El Descamisado (1973, 20 de mayo). Desalojos: última hazaña de la dictadura. 2, 11.

El Descamisado (1973, 24 de diciembre). Para construir las casas de los villeros nadie mejor que el pueblo villero. 32, 21 .

El Descamisado (1974). El pueblo ya marcó al culpable: el asesinato del compañero Chejolán. 46, 16-21.

Estrella, F. (1984). Arquitectura de sistemas al servicio de las necesidades populares 19641983 : teoría, práctica, políticas. México: Centro Experimental de Vivienda y Urbanismo.

Facultad de Arquitectura y Urbanismo (1973). Primer Congreso Nacional de la Vivienda Popular. Universidad Nacional de Buenos Aires

Gaite, A. (2007). Wladimiro Acosta: textos, proyectos, y obras testimonios sobre el maestro. Buenos Aires: Nobuko.

Giddens, A. (1984). The constitution of society. Cambridge: Polity Press.

Gillespie, R. (1982). Soldiers of Peron: Argentina's Montoneros. Oxford: Clarendon.

Gorelik, A. (2014). Miradas cruzadas. El viaje latinoamericano del planning norteamericano. Bifurcaciones, 18, 1-20.

Guevara, E. Che (1985 [1977]). Ernesto Che Guevara: escritos y discursos. La Habana: Editorial de Ciencias Sociales.

Inter-American Economic and Social Council (1954). Problems of housing of social interest. Washington, D.C.: Pan-American Union. 
La Hora (1958, 24 de mayo). Varias villas de emergencia se organizan en San Martín contra el fantasma del desalojo.

La Voz de las Villas (1965, febrero). Lo urgente es mejorar y no erradicar sin plan.

La Voz de las Villas (1969, agosto). Viviendas dignas: ni desalojos ni alojamientos transitorios.

La Voz de las Villas (1970a, abril). Proyecto de programa.

La Voz de las Villas (1970b, abril). Villa Mitre contra la erradicación y los desalojos.

Latour, B. (2005). Reassembling the social: an introduction to actor-network-theory. Oxford: Oxford University Press.

Longoni, R., Galcerán, V. E., Molteni, J. C., Pérez, R., Carranza, M., Fonseca, I. \& Bottega, C. (2009). El Departamento de Arquitectura UNLP. Primeros egresados. Primeras obras. Ponencia presentada en las Jornadas de Investigación de la FAU 2009, La Plata.

Longoni, R., Molteni, J. C., Galcerán, V. E. \& Fonseca, I. (2011). Vivienda y estado bonaerense (1956-1976). Ponencia presentada en el XIII ${ }^{\circ}$ Congreso de Historia de los Pueblos de la Provincia de Buenos Aires, Chivilcoy.

Massidda, A. L. (2012). The Plan de Emergencia (1956): housing shortage in Buenos Aires then and now. Scroope: The Cambridge Architecture Journal, 21, 42-51.

Massidda, A. L. (en prensa). Utopian visions for Buenos Aires shantytowns: collective imaginaries of housing rights, upgrading and eviction (1956-2013). Bulletin of Latin American Research.

Ministerio de Bienestar Social (1968). Plan de Erradicación de las Villas de Emergencia de la Capital Federal y el Gran Buenos Aires: Primer programa - erradicación y alojamiento transitorio. Buenos Aires: Ministerio de Bienestar Social.

Ministerio de Obras Públicas (2013). Historia de la vivienda social en la Provincia de Buenos Aires. Provincia de Buenos Aires. Recuperado de http://www.vivienda.mosp.gba. gov.ar/institucional/vivsocial.pdf [último acceso 20 de mayo 2013; actualmente no disponible].

Municipalidad de la Ciudad de Buenos Aires, Dirección General de Estadística y Censos (1962). Censo 1962. Villas de Emergencias. En Boletín $N^{\circ} 3$.

Nuestra Arquitectura (1973a). Número 483 completo.

Nuestra Arquitectura (1973b). Número 488 completo.

Nuestra Arquitectura (1973c). Plan Piloto de Realojamiento Barrio de Emergencia No 7 (488), pp. 28-32.

Nuestra Palabra (1963a, 5 de marzo). ¡Esas casas son suyas! Ocupantes del Barrio Almirante Brown.

Nuestra Palabra (1963b, 20 de agosto). Las “villas miserias" pasan a la ofensiva: puntos del memorial presentado a Illia.

OED Online (2016). Agency, n. Oxford University Press. Recuperado de http://www.oed. com/view/Entry/3851?redirectedFrom=agency [consultado el 4 de octubre de 2016]. 
Oszlak, O. (1991). Merecer la ciudad: los pobres y el derecho al espacio urbano. Buenos Aires: CEDES/Hvmanitas.

Pelli, V. (1974). Sistema unNE unO. Córdoba: Facultad de Arquitectura y Urbanismo, Universidad Nacional de Córdoba.

Pelli, V. (2006). Habitar, participar, pertenecer: acceder a la vivienda: incluirse en la sociedad. Buenos Aires: Nobuko.

Pradilla, E. (1982). Autoconstrucción, explotación de la fuerza de trabajo y políticas de estado en América Latina. En Pradilla, E. (ed.), Ensayos sobre el problema de la vivienda en América Latina. Ciudad de México: Universidad Autónoma Metropolitana-Xochimilco.

Provincia de Buenos Aires (1962). Ley 6.707.

Ratier, H. (1971). Villeros y villas miseria. Buenos Aires: Centro Editor de América Latina.

Ricchezza, A. (2002). Autoconstrucción: esfuerzo propio, ayuda mutua: un sueño o una realidad. Buenos Aires: Dunken.

Romero, L. A. (2012). Breve historia contemporánea de la Argentina 1916-2010 (3a ed.). Buenos Aires: Fondo de Cultura Económica.

Selser, G. (1964). Alianza para el Progreso: la mal nacida. Buenos Aires: Iguazú.

Smithson, A. (ed.). (1968). Team 10 Primer. Cambridge, Mass.: Mit Press.

Snitcofsky, V. (2011). Villas de Buenos Aires y conflictos portuarios bajo el gobierno de Onganía: aportes para un análisis de la articulación entre sindicalismo de base y organización territorial. En Basualdo, V. (ed.), La clase trabajadora argentina en el siglo Xx: experiencias de lucha y organización (pp. 51-80). Buenos Aires: Cara o Ceca.

Summa (1971a). Viviendas “El Saladero”, Bahía Blanca, Buenos Aires. 36, 84.

Summa (1971b). Número 43 completo.

Summa (1974). Número 72 completo.

Taffet, J. (2007). Foreign aid as foreign policy: the Alliance for Progress in Latin America. London: Routledge.

Tarcus, H. (2008). El mayo argentino. OSAL, 24, 161-80.

Till, J. (2005). The negotiation of hope. En Blundell Jones, P., Petrescu, D. \& Till, J. (eds.), Architecture and participation (pp. 23-42). London: Spon Press.

Trama (1982). Barrio Justo Suárez: Plan Piloto Realojamiento Villa 7. 3, 10-20.

Turner, J. F. C. (ed.) (1963). Dwelling resources in South America. Architectural Design, Special Issue, 8.

Turner, J. F. C. (1965). Lima's barriadas and corralones: suburbs versus slums. Ekistics, 19(112), 152-155.

Turner, J. F. C. (1967). Barriers and channels for housing development in modernizing countries. Journal of the American Institute of Planners, 33(3), 167-81.

Unión Panamericana (1958). Informe de la Secretaría de Consejo Interamericano Económico y Social sobre la Primera Reunión Técnica Interamericana en Vivienda y Planeamiento, celebrada en Bogotá, Colombia, entre el 26 de noviembre y el 7 de diciembre de 1956. 
Washington, D.C.: Unión Panamericana. Secretaría General, Organización de los Estados Americanos.

Yujnovsky, O. (1984). Claves políticas del problema habitacional argentino (1955-1981). Buenos Aires: Grupo Editorial Latinoamericano.

Ziccardi, A. (1977). Políticas de vivienda y movimientos urbanos: el caso de Buenos Aires (1963-1973). Buenos Aires: Centro de Estudios Urbanos y Regionales, Instituto Torcuato di Tella.

Ziccardi, A. (1984). El tercer gobierno peronista y las villas miseria de la ciudad de Buenos Aires (1973-1976). Revista Mexicana de Sociología, 46(4), 145-172. 